\title{
Relationships between the British Standard tests for workability and the two-point test*
}

\author{
G. H. Tattersall
}

\author{
Contribution by P. F. G. Banfill \\ University of Liverpool, Department of Building Engineering
}

Dr Tattersall's equation of correlation between the British Standard workability tests shows adequate agreement on a subjective level with the various sets of data referred to, but he has clearly been hampered by the lack of published values of experimental error for the tests. For instance, Dewar ${ }^{(1)}$ simply assumed values for testing errors which are clearly based on an estimate of how accurately the operator can use the equipment rather than on any measurement of the inherent variability of the tests.

With such a variable material as concrete, valid estimates of experimental error can be obtained only from properly designed experiments where the data can be processed statistically. Orr ${ }^{(2)}$ describes a factorial experiment where the compacting factor was measured and I have carried out similar experiments for slump and Vebe. The estimates of error obtained are summarized in Table $I$. With these estimates of error, the significance of the deviations shown in Table 7 of Dr Tattersall's paper can be investigated.

For a linear equation of the form

$$
p=a_{1} x+a_{2} y+a_{3} z
$$

the variance in $p$ can be expressed in terms of the variances of $x, y$ and $z$ :

$$
\sigma_{\mathrm{p}}{ }^{2}=a_{1}{ }^{2} \sigma_{\mathrm{x}}{ }^{2}+{a_{2}}^{2} \sigma_{\mathrm{y}}{ }^{2}+a_{3}{ }^{2} \sigma_{\mathrm{z}}{ }^{2}
$$

The corresponding expression for Dr Tattersall's equation 10

$$
4 \cdot 55 V+255 S^{*}+1010 C=1000
$$

is:

$$
\sigma^{2}(\mathrm{~F})=\left(4 \cdot 55 \sigma_{\mathrm{v}}\right)^{2}+\left(255 \sigma_{\mathrm{s}}{ }^{2}\right)^{2}+\left(1010 \sigma_{\mathrm{c}}\right)^{2}
$$

Now $S^{*}=f(s)=S^{-1 / 2}$

*Pages 143 to 147 of $M C R 96$
Therefore $\sigma_{\mathrm{s}}^{*}=\mathrm{f}(s) \sigma_{\mathrm{s}}=-1 / 2 S-{ }^{3 / 2} \sigma_{\mathrm{s}}$

Substituting this into equation I gives

$\sigma^{2}(\mathrm{~F})=20 \cdot 7 \sigma_{\mathrm{v}}{ }^{2}+16256 S^{-3}{\sigma_{\mathrm{s}}}^{2}+1 \cdot 02 \times 10^{6} \sigma_{\mathrm{c}}{ }^{2}$

Using equation II to obtain estimates of the variance of $\mathrm{F}$ at low, medium and high workabilities gives the data in Table II.

The values for $S, C$ and $V$ at low workability are taken from Hughes's data, whilst the others are reasonable assumptions based on experience. The important point about Table II is the huge error incurred at low workability, due to the combined effects of the errors in $S$ and $V$.

\section{T A B LE I : Estimates of error on British Standard} workability tests.

\begin{tabular}{l|c|c|c|c}
\hline \multicolumn{1}{c|}{ Test } & $\begin{array}{c}\text { Range } \\
\text { of } \\
\text { values }\end{array}$ & $\begin{array}{c}\text { Standard } \\
\text { deviation } \\
\text { of error }\end{array}$ & $\begin{array}{c}\text { Degrees } \\
\text { of } \\
\text { freedom }\end{array}$ & $\begin{array}{c}\text { Dependence } \\
\text { of } \sigma \text { upon } \\
\text { response }\end{array}$ \\
\hline $\begin{array}{l}\text { Compacting } \\
\text { factor }\end{array}$ & $0 \cdot 75-1 \cdot 0$ & $\sigma_{\mathrm{s}}=0 \cdot 024$ & 60 & independent \\
\hline Slump & $0-100 \mathrm{~mm}$ & $\sigma_{\mathrm{s}}=11$ & 21 & independent \\
\hline Vebe & $1-24 \mathrm{~s}$ & $\sigma_{\mathrm{s}}=0 \cdot 25 \mathrm{~V}$ & 23 & $\begin{array}{l}\text { constant } \\
\text { coefficient } \\
\text { of variation }\end{array}$ \\
\hline
\end{tabular}

T A B LE II: Values of error in F at different workabilities.

\begin{tabular}{l|c|c|c|c|c}
\hline \multirow{2}{*}{ Workability } & \multicolumn{3}{|c|}{ Values from B.S. tests } & \multicolumn{2}{c}{ Errors in F } \\
\cline { 2 - 6 } & $s$ & $c$ & $V$ & $\sigma^{2}(\mathrm{~F})$ & $\sigma(\mathrm{F})$ \\
\hline Low & 7.5 & 0.75 & 15 & $5541 \cdot 1$ & 74.4 \\
Medium & 20 & 0.90 & 6 & 880.0 & 29.7 \\
High & 100 & 0.98 & 1.5 & 593.2 & 24.3 \\
\hline
\end{tabular}


T ABLE III: Significance of variations about equation 10.

\begin{tabular}{l|c|c|c|c|c|c}
\hline Reference & $\begin{array}{c}\text { Number of } \\
\text { results }\end{array}$ & $\begin{array}{c}\text { Mean value of } \\
\mathrm{F}\end{array}$ & $\begin{array}{c}\text { Variance of } \\
\text { individuals }\end{array}$ & $\begin{array}{c}\text { Error } \\
\text { variance }\end{array}$ & $\frac{\sigma^{2} \text { (ind) }}{\sigma^{2}(\mathrm{~F})}$ & $\begin{array}{c}\text { Ratio for 5\% } \\
\text { significance }\end{array}$ \\
\hline Singh & 84 & 1005 & $1030 \cdot 4$ & $880 \cdot 0$ & $1 \cdot 17$ & 1.90 \\
Dewar & 21 & 986 & $1640 \cdot 3$ & $880 \cdot 0$ & 1.86 & $2 \cdot 10$ \\
Hughes & 37 & 903 & $4395 \cdot 7$ & $5541 \cdot 1$ & 0.79 & 1.96 \\
Ritchie & 10 & 984 & $1391 \cdot 3$ & $880 \cdot 0$ & 1.58 & $2 \cdot 32$ \\
Banfill* & 146 & 1007 & $600 \cdot 3$ & $593 \cdot 2$ & 1.01 & 1.85 \\
\hline
\end{tabular}

${ }^{*}$ Unpublished information made available by Mr D. Monaghan, Civil Engineering Department, University of Liverpool.

These independently obtained estimates of error may now be used in a variance ratio rest of significance to compare the observed deviations of F quoted in Dr Tattersall's Table 7. The comparisons made assume the smallest of the three degrees of freedom in Table I-viz. 21-and the results are tabulated in Table III. Also included in Table III are comparisons for 146 results obtained in our laboratories, of which 128 were at high workability.

It is clear that the deviations are significant for none of the sets of data tested, even Hughes's which were largely outside the range of values used by $\mathrm{Dr}$ Tattersall in compiling equation 10 . This seems to confirm that the two-point workability test is applicable to the whole range of workabilities, but more importantly demonstrates the inadequacy of the British Standard tests when used for low-workability mixes. However, we have as yet no information on the errors involved in the two-point test which will become important at high workabilities where the test measures a small difference between two power consumptions.

In general, I endorse Dr Tattersall's conclusions and I would agree that it is high time we started measuring something related to a fundamental property of fresh concrete, instead of how much it slumps etc. It would be interesting to relate viscosity measurements to the behaviour of fresh concrete in other contexts-such as bleeding, segregation and the influence of internal vibration.

\section{Contribution by C. Ellis}

Sheffield City Polytechnic, Department of Civil Engineering

Dr Tattersall suggests a workability function $\mathrm{F}(S, V, C)$ of the form

$$
\mathrm{F}(S, V, C)=4 \cdot 55 \mathrm{~V}+255 S^{-0.47}+1010 C=1000
$$

where $S$ = slump in $\mathrm{mm}$;

$V=$ Vebe time in seconds;

$C=$ compacting factor.

The results in Table IV were extracted from an investigation into the behaviour of pfa/opc concretes and contain values of $F$ calculated from the results of the British Standard workability tests carried out in conjunction with the above investigation.

All results above were taken from concretes in the low-medium (5-80 $\mathrm{mm}$ slump) workability range. Opc control mixes were concrete mixes of nominally identical proportions, whilst $\mathrm{pfa} / \mathrm{opc}$ contained two types of pfa $\left(0-300 \mathrm{~kg} / \mathrm{m}^{3}\right)$ and one opc $(160-320$ $\left.\mathrm{kg} / \mathrm{m}^{3}\right)$.

T A B LE IV : Values of $F$ calculated from British Standard workability tests carried out in conjunction with the investigation discussed.

\begin{tabular}{l|c|c|c|c|c}
\hline \multicolumn{1}{c|}{ Reference } & $\begin{array}{c}\text { Number of } \\
\text { results, } \\
n\end{array}$ & $\begin{array}{c}\text { Mean } \\
\text { value of } \\
\text { F }\end{array}$ & $\begin{array}{c}\text { Standard } \\
\text { deviation, } \\
s\end{array}$ & $\begin{array}{c}\text { Standard error } \\
\text { of mean } \\
s\end{array}$ & $\begin{array}{c}\text { Student's } \\
t\end{array}$ \\
\hline opc control mixes & 12 & 987 & $14 \cdot 7$ & $4 \cdot 25$ & $959-1011$ \\
\hline pfa/ope various & 38 & 961 & $30 \cdot 9$ & $5 \cdot 00$ & $824-1002$ \\
\hline Combined results & 50 & 968 & $36 \cdot 4$ & $5 \cdot 15$ & $824-1011$ \\
\hline
\end{tabular}

$o p c=$ ordinary Portland cement $\quad$ pfa $=$ pulverized-fuel ash 
Notwithstanding the above observations and the ones cited by Dr Tattersall, the results suggest that, for concretes within the normal workability range, an expression of the general form postulated for $\mathrm{F}$ could apply. It is difficult, however, to test this hypothesis for low-slump (less than $5 \mathrm{~mm}$ ) concretes where the term $255 S^{-0.47}$ in the expression tends to infinity and for high-slump concretes where collapse slumps occur, thus invalidating this term in the expression.

\section{Reply by the author}

It is pleasing that both Mr Banfill and Mr Ellis find that their own results fit reasonably well into my equation, although the agreement for the pfa mixes is rather unsatisfactory. There is no apparent reason why the mere presence of pfa should affect the form of the relationship and it is perhaps important to note that $\mathrm{Mr}$ Ellis's mixes were of relatively low workability; both contributors pointed out, as I did myself, that at low slumps the value of $F$ is subject to large errors because of the hyperbolic term. It will be

\section{REFERENCES}

1. DEWAR, J. D. Relations between various workability control tests for concrete. London, Cement and Concrete Association, 1964. pp. 17. Technical Report 42.375 .
The results of Student's ' $t$ ' tests (where measured means of ' $F$ ' for each mix group are compared with the hypothetical $F=1000$ ) indicate significant differences between hypothetical and experimental values of $\mathrm{F}$ at the $5 \%$ probability level with all groups of data. However, at the $1 \%$ probability level, the hypothesis is vindicated for opc control mixes only, although these were of nominally identical proportions.

remembered that, for the sets of results given in the paper, the agreement was worst for those of Hughes, who had used low-workability mixes of zero or nearzero slump.

Mr Banfill's supposition that I had been hampered by lack of published values of experimental error is correct and I am grateful to him both for providing some and for drawing my attention to the information in Orr's paper ${ }^{(2)}$, which I had missed.

2. ORR, D. M. F. Factorial experiments in concrete research.Journal of the American Concrete Institute. Proceedings Vol. 69, No. 10. October 1972. 